И. В. Цветкова, Н. С. Мухаметшина. Онтологические аспекты экологической культуры

УДК 130.2

DOI: 10.18101/1994-0866-2020-1-13-22

\title{
ОНТОЛОГИЧЕСКИЕ АСПЕКТЫ ЭКОЛОГИЧЕСКОЙ КУЛЬТУРЫ
}

\section{(c) Цветкова Ирина Викторовна}

доктор философских наук, доцент, профессор

кафедры истории и философии,

Тольяттинский государственный университет

Россия, 445020, г. Тольятти, ул. Белорусская, 14 (центральный кампус)

E-mail: aleksandr.kozlov@mail.ru

\section{(C) Мухаметшина Наталья Семёновна}

доктор политических наук, профессор кафедры философии, Самарский государственный технический университет

Россия, 443086, г. Самара, Московское шоссе, 34, корпус 5

E-mail: nmukhametshina@mail.ru

В статье проанализированы особенности экологической культуры, которые отличают ее от видов традиционной культуры. Традиционные подходы к экологической культуре базируются на принципах антропоцентризма. Они находят отражение в методиках экологического воспитания и образования. Антропоцентризм рассматривает экологическую культуру как средство снижения ущерба природе. В частности, такой подход к экологической культуре представлен в педагогической науке. Его недостаток состоит в том, что он рассматривает экологическую культуру по аналогии с другими видами культуры (материальной, духовной). В статье предложен онтологический подход к экологической культуре, который основывается на принципах экологического гуманизма и устойчивого развития. Экологическая культура предназначена для разрешения противоречия между средой обитания человека и природными объектами. Средством разрешения этого противоречия выступает рациональное управление научно-техническим прогрессом и инновационным развитием.

Ключевые слова: онтология; противоречия; экологическая культура; система; экологические ценности; религиозные ценности.

\section{Для цитирования}

Цветкова И. В., Мухаметшина Н. С. Онтологические аспекты экологической культуры // Вестник Бурятского государственного университета. Философия. 2020. Вып. 1. С. 13-22.

Разработка понятия «экологическая культура» связана с преодолением кризиса, который переживает современная цивилизация в результате преобразования природы. В процессе становления индустриального и постиндустриального общества человечество столкнулось с последствиями изменения окружающей среды, которые представляют угрозу для существования человечества. По мнению ученых, данный кризис вызван недостатком научных знаний о последствиях использования природных ресурсов, а также о влиянии современных технологий на природу. 
В последние десятилетия государства уделяют экологическим проблемам все больше внимания, как на национальном, так и на международном уровне. Однако усилия для решения экологических проблем не всегда приводят к желаемым результатам. Со времени проведения в 2009 г. Конференции ООН по изменению климата выбросы углерода возросли на $10 \%$ во всем мире, как отмечают зарубежные исследователи R. Maxwell и T. Miller [1]. Эта цифра является обескураживающим напоминанием о том, что 195 (потенциальных) стран подписали Парижское соглашение по климату 2015 г. Согласно рекомендациям Межправительственной группы экспертов по изменению климата необходимо сокращение выбросов углерода на 20 миллиардов тонн в течение двадцати лет и на семь миллиардов тонн к 2050 г. Это самые минимальные оценки того, что необходимо сделать для улучшения окружающей среды. В настоящее время не удалось перестроить социально-экономическое развитие государств в соответствии с критериями устойчивого будущего. Сложившая ситуация свидетельствует о необходимости углубления понимания того, что определяет сущность экологического кризиса и пути выхода из него.

Понятие «экологическая культура» широко применяется в современной науке, в образовании, практике социального управления. Его используют для обозначения одного из средств, оказывающих влияние на решение экологических проблем, с которыми столкнулось человечество в условиях современной цивилизации. Данное понятие характеризует усилия человечества по разрешению противоречий между постиндустриальным обществом и природой.

Цель статьи состоит в анализе экологической культуры в онтологическом аспекте. Это предполагает выделение специфики взаимодействия человека в условиях постиндустриального общества с природной средой. Онтологический подход к изучению экологической культуры дает возможность выявить особенности экологической культуры. По сравнению с другими разновидностями культуры, которые базируются на идеях антропоцентризма и гуманизма, анализ экологической культуры требует их критического пересмотра.

Ценности гуманизма и антропоцентризма находят воплощение в педагогическом подходе к экологической культуре. Во многих научных публикациях экологическую культуру рассматривают как цель экологического воспитания и образования. Экологическая культура выступает как результат просвещения, она базируется на ценностях гуманизма. Распространение знаний о природе, о состоянии окружающей среды, об экологическом ущербе, наносимом природе современной промышленностью, способно изменить сознание людей, активизировать деятельность по сохранению природы согласно педагогическому подходу к экологической культуре.

С позиций педагогики экологическая культура предстает как результат формирования знаний, умений, навыков, которые систематизируют социальноэкологический опыт, полученный личностью в результате воспитания.

В. Г. Кезин отмечает, что экологическую культуру в современной педагогике рассматривают в двух направлениях [2]. В рамках первого направления эколо- 
И. В. Цветкова, Н. С. Мухаметшина. Онтологические аспекты экологической культуры

гическая культура предстает как результат образования. Обучение знаниям, умениям и навыкам в области охраны среды обитания человека входит в приоритетные задачи экологического образования. В процессе экологического образования знания дополняются формированием системы нравственных и эстетических ценностей, характеризующих бережное отношение к природе. Нормативный аспект экологического образования воздействует на экологическое сознание, создавая представления о правовых рамках, определяющих взаимодействие социума с окружающей средой. Деятельностный аспект экологической культуры предполагает формирование умений экологического характера, которые интегрированы в различные виды человеческой деятельности.

Второе направление подчеркивает самостоятельное значение экологического воспитания, объясняя это сложностью задач формирования экологической культуры, которые не могут быть решены в рамках традиционных видов воспитательной деятельности. Экологическое воспитание дополняет другие виды современного воспитания, направленные на всестороннее развитие личности. Экологическое воспитание направлено на формирование экологического сознания, которое базируется на освоении обучающимися экологических знаний, приобретении экологических умений и навыков.

В. Г. Кезин выделяет в качестве универсальных элементов экологической культуры экологические отношения. Они имеют три формы проявления: познавательное, нравственное и эстетическое [2]. Познавательное отношение к природе основывается на научном познании законов природы, их применении для регулирования взаимосвязей между обществом и природой. Научные знания дают возможность определить место человека в природе, сформировать ответственное отношение за использование ее ресурсов.

Нравственное отношение предполагает распространение сознательного регулирования деятельности на природные объекты. В этой парадигме стремление к сохранению и приумножению природы выступает как проявление добра. Бесконтрольное использование природных ресурсов, нанесение ущерба окружающей среде предстает как зло.

Эстетическое отношение к природе проявляется в рассмотрении ее как источника красоты, стремления к совершенству. Образы природы, отражаясь в искусстве, воплощаются в традициях национальных культур.

Различные аспекты экологических отношений находят воплощение в экологическом сознании, эмоционально-чувственной сфере, а также в различных видах практической деятельности. В зависимости от подсистем экологической культуры исследователи делают попытку определить критерии экологической культуры: информационно-познавательные, эмоционально-чувственные, деятельностные. Они необходимы для оценки результатов педагогической деятельности. Познавательное отношение к экологическим проблемам выражается в информированности индивидов о сущности экологических проблем, способах их решения. В качестве критериев формирования информационно-познавательной подсистемы экологической культуры выступает заинтересованность личности в 
получении знаний о состоянии окружающей среды, знание нормативно-правовой базы, регулирующей природоохранную деятельность.

Эмоционально-чувственное отношение к природе измеряется показателями развития ценностной направленности личности. Критериями его формирования, в частности, выступает понимание особенностей национальной культуры во взаимосвязи с уникальными природными условиями.

Практические аспекты экологической культуры воплощаются в готовности и стремлении личности к реализации в своей деятельности экологических норм. В педагогике критериями практической составляющей экологической культуры выступают установки личности на участие в деятельности по сохранению природной среды.

Данные подсистемы экологической культуры тесно взаимосвязаны между собой, они определяют единство экологических ценностей и способов их практической реализации.

Экологическая культура рассматривается как целостная система, которая определяет рациональное отношение человека к природе, направленное на сохранение и приумножение природных ресурсов. Важными направлениями экологической культуры выступают формирование экологического сознания, экологической ответственности, которые опираются на систему экологических ценностей [3].

Однако педагогический подход к формированию экологической культуры не является эффективным для решения современных экологических проблем. Как показывают результаты мониторинговых исследований, проведенных в России в период с 1996 по 2017 г., усилия по реализации программ экологического просвещения не являются достаточными. Вероятно, это связано со снижением интереса государства к реализации экологических программ. Экологическая культура российского общества характеризуется потребительскими установками, ориентацией на индивидуализм, как отмечает Л. Ю. Иванова [4]. Данные факты свидетельствуют о том, что существует необходимость в пересмотре базовых принципов понимания экологической культуры, которые находят применение не только в педагогике, но и в других сферах деятельности, связанных с изменением экологического сознания (в политике, инновациях, управлении и т. д.)

В современной педагогической науке в качестве основы предлагается рассматривать ценностное отношение к природе. При этом его сущность раскрывается на основе антропоцентрической модели. Природа как ценность рассматривается через призму человеческих потребностей и интересов.

Необходимость экологической культуры вызвана глубокими преобразованиями, которые происходят во взаимодействии природы и общества. Они находят проявление в обострении ряда противоречий, которые проявляются на уровне различных аспектов человеческого бытия.

Онтологический аспект экологической культуры связан с необходимостью разрешения противоречий между естественными и искусственными объектами и процессами. Различие между «естественным» и «искусственным», которое суще- 
И. В. Цветкова, Н. С. Мухаметшина. Онтологические аспекты экологической культуры

ствовало в традиционной культуре, утрачивает свое значение. На начальном этапе индустриальной цивилизации под естественным понимали то, что существует в природе в виде ресурсов и может быть приспособлено и преобразовано для удовлетворения потребностей людей. Соответственно, искусственным являются такие объекты, материалы, процессы, которые отсутствуют в природе, но необходимы для реализации определенных интересов людей. Например, продукты современной химии возникают в результате преобразования природных веществ, но при этом получают свойства, которые отсутствуют в естественном состоянии.

По мере развития научно-технических знаний сфера искусственного расширяется, происходит стирание резких граней между естественным и искусственным, а также между искусственным и природным. Река до строительства на ней электростанции была естественным ресурсом, который люди использовали для различных хозяйственных целей. Строительство на реке электростанции преобразовало реку в объект, который приобрел характеристики искусственного, технического объекта. Возведение гидроэлектростанции изменило русло реки, преобразовало ее естественные свойства. Выполняя технические функции выработки электроэнергии, река осталась рекой, но изменила свои природные свойства: качество воды, глубину, состав живых организмов, которые обитают в воде и по берегам. Произошли изменения в составе воздуха, климате, в ареалах обитания растений и животных, которые, как правило, имеют негативный характер. В связи с тем, что природный объект люди используют для выполнения технических функций, возникают проблемы, связанные с регулированием состояния окружающей среды.

Изменения природных объектов, которые произошли под влиянием технологий индустриального общества, невозможно вернуть к изначальному состоянию. Экологическая культура не может остановить процессы создания среды обитания людей с использованием технических средств. Она необходима для того, чтобы поставить под рациональный контроль условия существования не только людей, но природных комплексов.

По мере развития научно-технического прогресса человек окружает себя искусственной средой обитания, в которую встроены природные подсистемы. Это объективный процесс развития общества, который выступает одним из факторов эволюционного преобразования природы. Например, существуют проекты создания плавучих городов, которые будут перемещаться по поверхности мирового океана. Если данные проекты будут реализованы, то океаны будут испытывать влияние искусственной урбанистической среды. Это приведет к тому, что природные объекты мировых океанов также будут нуждаться в рациональном управлении. Таким образом, экологическая культура включает систему средств, которые регулируют взаимодействие человечества с природой в процессе создания среды обитания, преобразованной при помощи техники.

Онтологические аспекты экологически культуры требуют кардинального пересмотра базового отношения человека к природе. В эпоху индустриальной цивилизации преобладало потребительское отношение к природе. Ее рассматри- 
вали как источник ресурсов для хозяйственной деятельности. Соответственно, охрана природы была направлена на восполнение некоторых видов ресурсов, высадку лесов, создание заповедников, запрет на отстрел животных и т. Д. Деятельность по охране природы служит своего рода компромиссом в условиях общества массового потребления между ростом потребностей и попыткой восстановить использованные ресурсы.

На современном этапе развития цивилизации природоохранная деятельность не утратила своего значения. Однако она не является достаточной для преодоления противоречий между ростом потребностей человечества и нагрузкой на природную среду. В современных условиях назревает необходимость рационального управления различными аспектами хозяйственной деятельности людей, которые касаются не только объемов потребляемых ресурсов, но также рационального использования того, что превратилось в отходы. Данная проблема включает утилизацию искусственных материалов, которые представляют опасность для биосферы.

Рациональное управление искусственной средой и природными системами в качестве базового отношения экологической культуры предполагает получение и практическое применение новых научных знаний. Экологическая культура опирается на комплексные знания о природе, обществе, технике, человеке. Они необходимы для прогнозирования последствий научно-технического прогресса, их влияния на эволюцию природы и общества. Для современной науки приоритетным направлением является разработка технологий, которые дают возможность создавать и внедрять инновации. Экологическая культура опирается на систему знаний, которые определяют нормативы и ограничения для развития инноваций. Эти рамки необходимы для оценки возможного ущерба среде обитания людей, а также природе.

С позиций экологической культуры инновации измеряются не только технической и социально-экономической целесообразностью. Большое значение имеет оценка того, какие ближайшие и отдаленные последствия будет иметь повышение эффективности технических устройств. Перспективным направлением современной энергетики является использование новых источников энергии: солнечного света, энергии океана, термальных источников. Данные технические устройства рассматриваются как альтернатива атомной энергетике, гидроэлектростанциям. Однако сегодня отсутствуют комплексные сведения о последствиях внедрения этих инноваций в области энергетики для природы. Для развития экологической культуры необходимо учитывать не только преимущества новых технологий по сравнению со старыми, но и разнообразные аспекты их влияния на окружающую среду.

Экологическая культура, которая базируется на рациональном управлении средой обитания человека и природными системами, находится в противоречии с современными социально-экономическими отношениями. Объективные закономерности капиталистической экономики, которые порождают социальное неравенство, создают препятствия для практической реализации требований экологи- 
И. В. Цветкова, Н. С. Мухаметшина. Онтологические аспекты экологической культуры

ческой культуры. Современная экономика базируется на расширении доступности материальных благ, что с неизбежностью приводит к увеличению потребления природных ресурсов, к возрастанию технической и антропогенной нагрузки на природную среду.

Пропаганда потребления экологически чистых продуктов выступает одним из стимулов экономического развития, которое в определенной степени способствует внедрению «зеленых» технологий, но порождает ряд социальных проблем. Возникают новые аспекты социального неравенства, которые выражаются в критериях уровня и качества жизни, включающих экологические параметры. Слои общества с высокими доходами могут обеспечить стандарты образа жизни «в гармонии с природой», а люди с низким достатком довольствуются минимумом жизненных средств. Поскольку численность людей с высокими доходами не велика, мода на экологически чистую продукцию не может существенно повлиять на решение экологических проблем в масштабах цивилизации.

Таким образом, реализация экологической культуры предполагает изменение приоритетных целей и стимулов социально-экономического развития общества. Критерии экономической и социальной эффективности должны согласовываться с представлениями об экологическом равновесии. Для современной цивилизации большое значение имеют критерии устойчивого развития, которые согласовывают показатели экономического развития с задачами социальной политики и поддержанием состояния окружающей среды с учетом интересов будущих поколений. Распространение идей устойчивого развития находит отражение в международных документах, государственных программах, однако в настоящее время они выступают в качестве идеологических установок, которые трудно применить на практике. Как отмечает Э. В. Гирусов, принятое на глобальном форуме «Рио-92» решение о разработке общей концепции устойчивого развития и создании национальных программ к 1995 г. осталось нереализованным. Отсутствуют экономические и правовые механизмы, стимулирующие государства к достижению устойчивого развития [5].

Реализация целей устойчивого развития в качестве условий формирования экологической культуры предполагает глубокое преобразование экономического базиса современного общества, а также преобразование системы нравственных ценностей.

Культура базируется на систематизации опыта многих поколений, поэтому опирается на традиции. Истоки экологической культуры находятся в религиозных ценностях. Современную экологическую культуру сближает с религиозными ценностями обращение к преобразованию образа жизни на основах нравственности. Экологическая культура призывает к рациональному контролю над деятельностью и к достижению компромиссов.

Экологическая культура опирается на идею о ценности естественного существования во всех ее проявлениях. Это относится ко всем видам естественных объектов, а не только к уникальным созданиям природы. Экологические ценности охватывают каждую реку, дерево, животное, экосистему или ландшафт. Эко- 
логическое мышление обнаруживает ценность в каждом выражении природного разнообразия. Критерии биологического разнообразия важны для поддержания экологического равновесия. Признание разнообразия в способе существования предполагает поиск адекватных средств по отношению к каждому случаю, что требует практического воплощения экологических ценностей.

Экологическая культура предполагает изменение отношения к парадигме антропоцентризма, которая формировалась в европейской философии начиная с эпохи Возрождения. Антропоцентризм рассматривает человека как свободное существо, которое в своих действиях руководствуется моральными принципами. Ответственность человека в рамках традиционной морали распространяется на отношения с другими людьми и регулируется социальными институтами. Антропоцентрическое видение оправдывает абсолютное господство человека над низшими существами.

Экологическая культура возлагает ответственность на человека не только за отношения с людьми, но и за ущерб, который он наносит окружающей среде. Библейский миф об изгнании человека из рая может быть интерпретирован как наказание за нарушение естественной гармонии в отношениях с природой. Безудержное стремление к выгоде приводит к тому, что люди разрывают изначальные связи своего существования и создают угрозу гибели цивилизации.

Свобода дает также, согласно христианству, возможность искупления, в том числе и на Земле. Человек может измениться, стать другим. И у него есть способность вмешиваться в природу исцеляющим, обогащающим образом. Возможность увеличения природного богатства или сохранение его является естественной способностью, свойственной человеку. Однако реализация этих возможностей сталкивается с ростом потребностей человека. Таким образом, человек обладает своего рода господством, которое никогда не было предоставлено ему морально. Испанский философ J. Puig предлагает новую трактовку христианской доктрины, согласно которой сила Творца проявляется в создании Вселенной, богатстве экосистем и жизни, а не в их потреблении [6]. Мыслитель считает, что необходимо обратиться к истокам религиозной традиции, чтобы сформировать альтернативу антропоцентризму. Христианский подход к поиску оснований экологической культуры основывается на оптимистическом убеждении в том, что человек способен рационально регулировать свои потребности, соотнося их с императивами нравственности. Таким образом, искания современных христианских мыслителей направлены на расширение моральной ответственности человека на сферу взаимоотношений с природой.

Некоторые современные исследователи в качестве альтернативы антропоцентризму предлагают концепцию экологического гуманизма. В традиционном гуманизме культура предстает как сфера реализации человеческой свободы, которая воплощается в создании материальных и духовных ценностей, предназначенных для развития и совершенствования человека. Экологический гуманизм подчеркивает значимость природной основы бытия человека, которое выражается в признании самостоятельной ценности природы. Если традиционный гума- 
И. В. Цветкова, Н. С. Мухаметшина. Онтологические аспекты экологической культуры

низм рассматривал природу как «мастерскую», которая дает возможность проявить творческие возможности человека, то экологический гуманизм подчеркивает тесную взаимосвязь возможностей существования человека и сохранения природной среды. Таким образом, отношение «господства над природой», «подчинения природы интересам человека» в рамках экологического гуманизма должно быть заменено отношениями «ответственного управления» и «рационального контроля» [7].

Экологическая культура - это система рационального управления средой обитания человека и природными системами с целью обеспечения устойчивого развития современной цивилизации на основе ценностей экологического гуманизма. Данное определение, по нашему мнению, характеризуют онтологические особенности экологической культуры. Традиционная культура основывалась на сохранении баланса с окружающей средой, на первый план она выдвигала цели совершенствования человека. Экологическая культура занимает особое место в системе императивов современной цивилизации. Она возникает под влиянием современного научно-технического прогресса, который расширяет границы среды обитания человека, поэтому главные функции экологической культуры направлены на разрешение противоречий между природными основами бытия человека и деятельностью по созданию объектов, удовлетворяющих разнообразные потребности современной цивилизации.

Статья подготовлена при поддержке гранта РФФИ 18-411-630001 p_a «Концептуальная модель региональной идентичности населения Самарского региона».

Лuтература

1. Maxwell R., Miller T. Greening cultural policy // International Journal of Cultural Poliсу. 2017. № 23(2). P. 174-185.

2. Кезин В. Г. Экологическая культура и место экологических отношений в ее составе // Вестник ПНИПУ. Социально-экономические науки. 2014. № 3(24). С. 55-62.

3. Багдасарян А. А., Овсепян А. Ю. Экологическое сознание как компонент экологической культуры // Вопросы науки и образования. 2018. № 10(22). С. 167-170.

4. Ivanova L.Yu. The environmental culture in the Russian society as a condition for building eco-consciousness and behavior of the younger generation // Economic and Social Changes: facts, Trends, Forecast. 2019. Vol. 12, No. 1. P. 189-201.

5. Гирусов Э. В. Гуманистический потенциал экологической культуры // ЭСГИ. 2016. № 4(12). C. 103-107.

6. Puig J. Sensibilidad por el medio ambiente y cristianismo (Environmental sensitivity and Christianism) // Scientia et Fides. 2019. № 7(1) P. 73-96.

7. Сысак М. Н. Экологическая культура как форма экологического гуманизма // Приволжский научный вестник. 2013. № 12-1(28). С. 77-81. 
ONTOLOGICAL ASPECTS OF ENVIRONMENTAL CULTURE

\section{Irina V. Tsvetkova}

Dr. Sci. (Philos.), A/Prof., Prof. of History and Philosophy Department, Tolyatti State University

14 Belorusskaya St., Tolyatti 445020, Russia

E-mail: aleksandr.kozlov@mail.ru

\section{Natalya S. Mukhametshina}

Dr. Sci. (Polit.), Prof., Prof. of Philosophy Department, Samara State Technical University

5/34 Moscow Highway, Samara 443086, Russia

E-mail: nmukhametshina@mail.ru

The article analyzes the features of environmental culture that distinguish it from the types of traditional culture. Traditional approaches to environmental culture are based on the principles of anthropocentrism. They are reflected in the methods of ecological education. Anthropocentrism considers environmental culture as a means of reducing damage to nature. In particular, such an approach to environmental culture is presented in educational science, but its disadvantage is that it regards ecological culture by analogy with other types of culture (material, spiritual). The article proposes an ontological approach to environmental culture, which is based on the principles of environmental humanism and sustainable development. Environmental culture is meant to resolve the contradictions between the human environment and natural objects. Rational management of scientific and technological progress and innovative development is a means for resolving these contradictions.

Keywords: ontology; contradictions; environmental culture; system; ecological values; religious values. 